\title{
ОСОБЕННОСТИ СМЫСЛОВОЙ СФЕРЫ ПОДРОСТКОВ В УСЛОВИЯХ ВКЛЮЧЕННОГО ОБУЧЕНИЯ
}

Абакумова И.В., Косикова Л.В.

В предлагаемой статье представлен материал по проблеме включенного (инклюзивного) образования в нашей стране, анализируются результаты исследования специфики ценностно-смысловой сферы подростков с ограниченными возможностями здоровья.

Ключевые слова: образовательная интеграчия, включенное образование, смысловая сфера, смысложизненная концепчия, смысловые стратегии.

В проекте Национальной образовательной инициативы «Наша новая школа» (2009) отмечается, что особое внимание должно быть сосредоточено на создании условий для полноценного включения в образовательное пространство и успешной социализации детей с ограниченными возможностями здоровья, детей с отклонениями в поведении, находящихся в трудной жизненной ситуации.

Происходящие социально-экономические преобразования в стране, активизация социальной политики по демократизации и гуманизации общества, развитие национальной системы образования обусловливают поиски путей совершенствования организации, содержания и методик обучения и воспитания детей с ограниченными возможностями.

Одним из путей реализации этой задачи является образовательная интеграция или включенное обучение (совместное получение образования обычными детьми и детьми с ограниченными возможностями), которое обеспечивает доступность образования для всех и выступает средством социальной интеграции.

В международной практике старый термин «интегрированное образование», описывающий данный процесс, был заменен термином «инклюзивное образование», «включенное образование».

Переход к включенному образованию в отечественном контексте в принципе уже был предопределен тем, что Россия ратифицировала Конвенции ООН в области прав детей, прав инвалидов: Декларация прав ребенка (1959); Декларация о правах умственно-отсталых (1971); Декларация о правах инвалидов (1975); Конвенция о правах ребенка (1975). Однако, чтобы Россия стала страной с цивилизованным образованием, нужно не только принять Закон о специальном образовании, или об образовании лиц с ограниченными возможностями, а иметь благоприятное 
общественное мнение по данному вопросу, а также создать институциальные условия для реализации прав инвалидов.

В настоящее время в стране насчитывается 617 тыс. детей-инвалидов, среди них обучается на дому около 34 тыс. детей и подростков с ограниченными возможностями здоровья.

Проблема социальной интеграции детей с нарушением развития является одной из важнейших научно-практических проблем, привлекающих к себе внимание отечественных (И.М. Гилевич, Э.И. Леонгард, Н.Н. Малофеев, М.И. Никитина, Т.В. Пелымская, Л.И. Тигранова. Л.М. Шипицына, Н.Д. Шматко и др.) и зарубежных (П. Бейкер, В. Гудонис, М. Джонсон, Д. Лауве и др.) ученых. В качестве приоритетного определяется психолого-педагогический аспект проблемы включенного обучения, к которому, прежде всего, относится выделение условий, способствующих эффективной интеграции. Специалисты отмечают, что проблема интеграции является сложной, многомерной, включающей много составляющих. Прогнозируются социальные трудности, заключающиеся в преодолении распространенных предрассудков и педагогических стереотипов, и организационные трудности, связанные с созданием так называемой безбарьерной среды, обеспечения не только эффективного, но и экономного пути развития образования детей с ограниченными возможностями. Особую актуальность приобретают исследования общественного мнения о проблемах образования, представлений школьников, их родителей, учителей о достоинствах и недостатках образования детей с ограниченными возможностями в условиях специальных образовательных учреждений и совместного обучения с обычными детьми.

Одной из актуальных проблем включенного обучения является изучение смысловой сферы детей и подростков с ограниченными возможностями. Исследование этой проблемы дает обширный материал для понимания личности подростков, что необходимо для последующего интегрирования их в общество. Актуализация проблемы смысла связывается с теми огромными изменениями, которые произошли в обществе и которые поставили перед человеком сложнейшие вопросы самоопределения, самооценки в новой исторической действительности. Смысловая сфера направляет поведение человека, определяет развитие личности, ее интересы, выбор жизненного пути, самоопределение человека, актуализируя его потенциал в будущем. Каждый человек имеет свою особенную, постоянно изменяющуюся и развивающуюся личностно-смысловую сферу, которая определяет большую склонность к той или иной смысложизненной концепции, что в свою очередь может определять выработку особых смысловых стратегий в процессе познания и взаимодействия с окружающим миром.

В ряде исследований по общей и педагогической психологии (И.В. Абакумова, А.Г. Асмолов, Д.А. Леонтьев, В.П. Зинченко, В.В. Знаков, Е.В. Клочко и др.) отмечается, что в качестве важнейших факторов развития личностной сферы ребенка можно рассматривать его смысловые характеристики, уровни развития его смысловых образований. И.В. Абакумова определяет индивидуальную смысложизненную 
стратегию как сформировавшуюся в ходе онтогенеза на основе ментального опыта систему личностных образований индивида, позволяющую оптимизировать или минимизировать активность субъекта во взаимоотношениях с объективной действительностью и проявляющуюся в отношении к цели, процессу, результату деятельности, а также в отношении к жизни и к самому себе [1].

Смысложизненная концепция начинает складываться к подростковому возрасту, она может изменяться и трансформироваться на протяжении жизни человека, но на определенном этапе онтогенеза является достаточно устойчивой. Период подросткового возраста наиболее восприимчив к социальным изменениям (Г.М. Андреева, Л.И. Божович, Л.С. Выготский, И.С. Кон, А.В. Петровский, Д.И. Фельдштейн, Д.Б. Эльконин).

В этом возрасте происходит «овладение внутренним миром», «возникновение жизненного плана как известной системы приспособления, которая впервые осознаётся подростком» [2]. У подростков создаются предпосылки для становления представлений о смысле жизни, поскольку это возраст открытия своего «я», оформления личности, с одной стороны, и возраст оформления мировоззрения - с другой. В подростковом возрасте происходит интенсивное развитие смысловых ориентиров, совершенствование смысловых ориентаций, созревание общей направленности личности. Внутренний мир и индивидуальные смысловые ориентации приобретают самодостаточность, которая может переходить в сверхценность; самосознание вызывает стремление к самоутверждению и самовоспитанию. Многие исследователи отмечают, что наибольшим достижением этого периода является бурное развитие рефлексии - осознание себя и возможных преобразований в окружении и самом себе. Благодаря развивающейся рефлексии закрепляются и совершенствуются осознаваемые установки личности, обретающие мотивирующую силу в организации и самоорганизации поведения подростка. По мере все большей представленности установок личности и исповедуемых ею ценностей в рефлексивном опыте растет значение влияния собственно личностных сил развития, таких как самооценивание, самоприятие, приятие других, социальная направленность личности, стремление к доминированию, выраженность интернальности в решениях и действиях и др.

М.А. Фризен отмечает, что в зависимости от открытости личности новому опыту возможно выделение двух типов развития смысловой сферы в подростковом возрасте: продуктивного и репродуктивного. Смысловая сфера, развивающаяся по продуктивному типу, может быть отнесена к классу активно-творческих, она характеризуется открытостью, рефлексивностью, как следствие, упорядоченностью, нестереотипностью, гармоничностью, «готовность следовать зову потенциального», то есть ставить и решать задачи на смысл, внутренней простроенностью генерализованных смыслов, гибкостью центрации сознания. Репродуктивному способу соответствует смысловая сфера, отличающаяся жесткой центрацией сознания и закрытостью, что может вести к ее дисгармоничности, малому объему нестереотипных смыслов, их неупорядоченности, преобладанием защитных механизмов 
над механизмами смыслообразования и смыслотворчества в случае возникновения задач на смысл [6].

Но если здоровый ребенок имеет возможность пробовать окружающую действительность, ошибаться, самостоятельно или с помощью взрослых исправлять ошибки, благодаря современным условиям общаться с разными людьми и создавать более адекватный образ будущего, при стремлении к которому будут формироваться необходимые личностные качества, то дети с проблемами в развитии часто лишены таких возможностей. Само заболевание, отношение окружающих и часто неправильный стиль воспитания дают искаженный образ будущего.

Изучение научной литературы и практики обучения детей с ограниченными возможностями позволили выявить ряд противоречий:

- между необходимостью организации включенного обучения детей с ограниченными возможностями и недостаточной разработанностью научно-теоретической и методической базы обучения этих детей;

- между потребностью детей с ограниченными возможностями здоровья в комплексной психолого-педагогической и медико-социальной реабилитации и отсутствием исследований об особенностях смысловой сферы таких детей, что затрудняет создание системы индивидуально-личностной поддержки их в процессе обучения и воспитания.

Целью нашего исследования является выявление специфики ценностносмысловой сферы подростков и разработка системы их психолого-педагогического сопровождения в условиях включенного обучения.

В исследовании приняли участие школьники-подростки 10 общеобразовательных школ г. Ростова-на-Дону, находящиеся на домашнем обучении (всего 74 чел). Учащиеся, находящиеся на домашнем обучении, представляют собой неоднородную группу: по принадлежности к определённой нозологической группе (неврологические заболевания, двигательные и сенсорные ограничения, соматические заболевания), возрасту и включённости в обучение (дети, которые учатся по общей программе, но расписание уроков не такое жесткое, как в школе, дети, вынужденные несколько раз в год проходить лечение в больнице (заболевания эндокринной системы) и дети-инвалиды, обучающиеся в обычном классе.

В настоящем исследовании использовались стандартизированные методики и методики проективного типа. Для выявления системы субъективных ценностей использовались тесты «Автопортрет», «Образ мира» (Е.С. Романова и О.Ф. Потёмкина) [5]. В рамках психометрического подхода к смысловой реальности учащихся были использованы: методика, основанная на методе семантического дифференциала «Шкала аттитюдов ко времени» и «Атрибуция личностных качеств» (К. Муздыбаев) [4] и тест смысложизненных ориентаций (Д.А. Леонтьев) [3].

С помощью описанных выше методик оказалось возможным получить данные, позволяющие установить особенности смысловых структур личности подростков с ограниченными возможностями здоровья: их жизненные ценности, 
содержательные аспекты самооценки, отношение к окружающему миру, эмоциональная оценка жизненных перспектив, локус контроля, смысловые стратегии.

Тест СЖО позволяет изучить особенности смысловой сферы учащихся, выделить уровень их смыслового развития как по интегрированному показателю - общая осмысленность жизни, так и по основным составляющим - смысложизненных ориентаций: цели в жизни, процесс жизни, локус контроля-Я и локус контроля-жизнь. Именно эти показатели оказывают влияние на личностное развитие подростков.

В результате обработки полученных данных по тесту СЖО было установлено, что в группе подростков с ограниченными возможностями (экспериментальная группа) интегрированный коэффициент осмысленности жизни и показатели по субшкалам: «цели в жизни», «процесс жизни», ЛК-Я и ЛК-жизнь значимо ниже (с достоверностью $\mathrm{p}<0,01$ по Mann-Whitney U Test), чем в контрольной группе (см. Таб. 1).

Таблица 1

Сравнительный анализ показателей данных по тесту СЖО

\begin{tabular}{|c|c|c|c|c|c|c|}
\hline \multirow[t]{2}{*}{ Группа учащихся } & \multicolumn{5}{|c|}{$\begin{array}{c}\text { Показатели смысложизненных } \\
\text { стратегий }\end{array}$} & \\
\hline & Цели & Процесс & Результат & ЛК-Я & ЛК-Ж & ОЖ \\
\hline $\begin{array}{l}\text { Дети-инвалиды, посещающие } \\
\text { школу }\end{array}$ & 25,79 & 31,21 & 22,89 & 18,71 & 29,11 & 90,14 \\
\hline Дети, находящиеся в больнице & 28,95 & 28,42 & 27,26 & 20,00 & 30,11 & 95,68 \\
\hline $\begin{array}{l}\text { Дети, находящиеся на домашнем } \\
\text { обучении }\end{array}$ & 28,67 & 29,44 & 23,67 & 19,78 & 27,19 & 94,59 \\
\hline Контрольная группа & 33,15 & 33,62 & 27,59 & 22,60 & 32,87 & $\overline{110, \varepsilon}$ \\
\hline
\end{tabular}

Для подростков с ограниченными возможностями здоровья в меньшей степени, чем для обычных школьников, характерны такие показатели смысловой сферы, как степень осмысленности жизненных проблем, наличие целей в будущем, эмоциональная насыщенность жизни, представление о себе как о сильной личности, способной конструировать и реализовывать те или иные планы, контролировать возникающие ситуации. Это может свидетельствовать о более пассивной позиции подростков с ограниченными возможностями в различных жизненных сферах, определённой личностной регрессии. В зависимости от включённости в обучение у подростков складывается различное отношение к жизни, вырабатывается особенная смысложизненная стратегия. Отличия смысложизненных стратегий связаны с различным отношением к процессу, результату и цели деятельности, а также в общем показателе - отношении к жизни.

При сравнении составляющих смысловой сферы (цель, процесс, результат, локус контроля-Я, локус контроля-жизнь) выделились следующие важные компоненты смысложизненных стратегий у подростков, находящихся на домашнем обучении, и у детей-инвалидов. Первую позицию занимает процесс. Различие в составляющих их смысложизненной стратегии заключается в ориентации на цели жизни и стремлении контролировать её и принимать самостоятельные решения. 
Подростки, находящиеся на домашнем обучении, в большей степени придают значение целям в будущем, чем дети-инвалиды. У подростков, проходящих лечение в больнице, на первом месте локус контроля - жизнь. Их отличает вера в способность управлять своей жизнью, что может говорить о некоторой степени самоуверенности и желании внешне показать себя сильными личностями.

Во всех трёх группах стремлению построить свою жизнь в соответствии со своими целями и представлениями о ее смысле, а также контролировать события собственной жизни придается минимальное значение. Этому аспекту следует придать особое внимание в коррекционной работе с данной группой подростков.

Основой смысложизненной стратегии учащихся, находящихся на домашнем обучении и детей-инвалидов, является настоящее, чтобы скрыть свою неспособность контролировать жизнь, цели и результаты. Характерной особенностью смысложизненной стратегии подростков с ограниченными возможностями является неверие в свои силы контролировать события собственной жизни. Они опасаются негативного влияния любых событий на свою жизнь. Это сочетается с внешним локусом контроля - экстернальностью, то есть, склонностью объяснять основную часть жизненных неудач внешними обстоятельствами. Подобное эмоциональное самочувствие оказывает негативное влияние на душевное благополучие, как родителей, так и их детей, на их отношения с окружающими и усиливает социально-психологические и личностные конфликты. Специфика социализации школьников с ограниченными возможностями здоровья состоит в снижении активности в сфере установления и изменения социальных отношений, увеличении риска дезадаптивных проявлений. Это может выразиться в росте эмоциональной напряжённости, появлении неадекватных психологических защит (типа агрессии, депрессии и т.п.).

Для выявления вербализуемого отношения к жизни в целом была использована оценка своей жизни по биполярным шкалам (основанная на методе семантического дифференциала методика «Шкала аттитюдов ко времени», адаптированная К. Муздыбаевым). Респондентам было предложено оценить свою жизнь по парам противоположных характеристик, поставив точку на шкале ближе к тому или иному полюсу. Шкалы изображались в виде одинаковых горизонтальных линий. Были предложены следующие шкалы для оценивания жизни: приятная - неприятная, насыщенная событиями - бедная событиями, опасная - безопасная, прекрасная - ужасная, полная надежд - безнадежная, быстро проходящая - долго тянущаяся, легкая - трудная, успешная - неудачная, интересная - скучная, светлая - темная, свободная - несвободная, бессмысленная - осмысленная, активная - пассивная, управляется мной - управляется другими людьми.

Учащиеся, находящиеся на домашнем обучении, оценивают жизнь противоречиво. Она представляется им насыщенной событиями, полной надежд, но в тоже время проявляется тенденция к оценке жизни нейтрально, в особенности по шкалам «прекрасная - ужасная», «успешная - неуспешная», «управляется мной - управляется другими людьми». Наиболее часты негативные оценки жизни по шкалам «лёгкая - трудная», «быстро проходящая - долго тянущаяся», «безопасная - опасная» (см. рис. 2). 


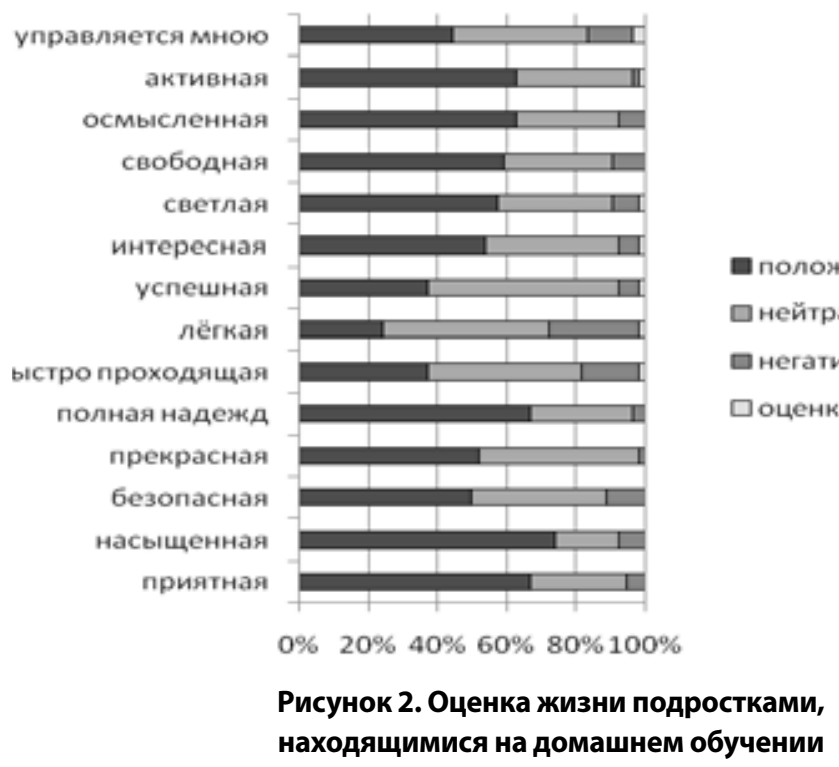

В процессе исследования было установлено, что специфические особенности смысловой сферы подростков с ограниченными возможностями детерминированы нарушениями, вытекающими из биологического характера состояния здоровья и нарушениями, возникающими в ходе социального развития ребенка, его взаимодействия с окружающим миром. Эти особенности проявляются в отношении к окружающему миру (недостаточная степень осмысленности смысложизненных проблем, проявление пассивной позиции в различных жизненных сферах, слабая эмоциональная насыщенность жизни); во взаимоотношениях с микросоциумом (социальная индифферентность, отгороженность, тенденция к ограничению социальных контактов, недостаточный уровень развития коммуникативных навыков); в содержательных аспектах самооценки (неадекватность самооценки, затруднения в эмоционально-ценностном отношении к себе, неверие в свои силы); в структуре жизненных ценностей (искажение субъективного образа мира, эмоциональная оценка жизненных перспектив, отказ от ответственности за себя и других); во внешнем локусе контроля (несамостоятельность, неумение контролировать события собственной жизни, зависимость жизненных планов от организации обучения).

Развитие смысловой сферы подростков с ограниченными возможностями, их смысложизненные ориентации определяются факторами их жизнедеятельности и изменяются под влиянием условий, создаваемых в процессе включенного обучения.

Система психолого-педагогического сопровождения подростков с ограниченными возможностями в условиях включенного обучения может быть организована 
по следующим направлениям: определение целей и приоритетов психологопедагогической помощи подросткам; комплексная диагностика здоровья и особенностей личностного развития ребенка специалистами разного профиля; выбор содержания и образовательных технологий обучения, направленных на актуализацию мотивационно-смысловой сферы подростков с учетом их возможностей; организация процесса обучения в соответствии с индивидуально-личностными особенностями ученика; повышение психолого-педагогической квалификации специалистов, работающих в системе включенного обучения.

\section{Литература}

1. Абакумова И.В. Обучение и смысл: Смыслообразование в учебном процессе. - Ростов н/Д: Изд-во Рост.ун-та, 2003.

2. Выготский Л.С. Собрание сочинений: в 6 тт. - Т.3. - М., 1984. - С. 327-328.

3. Леонтьев Д.А. Тест смысложизненных ориентаций (СЖО). - М.: Смысл, 1992.

4. Муздыбаев К. Жизненные стратегии современной молодёжи: межпоколенческий анализ //Журнал социологии и социальной антропологии. - Том VII. - № 1. 2004. - С. 175-189.

5. Романова Е.С., Потёмкина О.Ф. Графические методы в психологической диагностике. - М.: Дидакт, 1992.

6. Фризен М.А. Особенности развития смысловой сферы подростков. Автореф. дис. ... канд. психол. наук. - Хабаровск, 2005. 